\title{
EVALUASI KEPUASAN PENGGUNA TERHADAP RESPON CEPAT TANGGAP LAYANAN APLIKASI MOBILE MYINDIHOME BERDASARKAN KOMBINASI METODE SERVQUAL DAN METODE WEBQUAL
}

\author{
Endah Saputri \\ Program Studi Magister Teknik Informatika \\ Universitas Bina Darma Palembang \\ Email: endahsaputri@gmail.com
}

\begin{abstract}
ABSTRAK
Penelitian ini bertujuan untuk mengetahui tingkat kepuasan pengguna aplikasi mobile myindihome. Dalam penelitian ini, pengukuran kepuasan pengguna terhadap respon cepat tanggap layanan menggunakan kombinasi metode ServQual dan WebQual. Kombinasi kedua teori, secara efektif menangani multikolinieritas (jika banyak variabel yang sangat berkorelasi). Sehubungan dengan kondisi itu, berdasarkan teori service quality (ServQual) digunakan untuk mengetahui kepuasan terhadap aplikasi tersebut, apakah ada pengaruh variabel reliability, responsiveness, empathy, assurance, dan tangible terhadap kepuasan pengguna baik perorangan maupun kelompok. Sedangkan berdasarkan instrumen webqual 4.0 mengidentifikasi kualitas berdasarkan tiga variabel yaitu usability, information quality, dan service interaction quality. Penelitian ini diharapkan dapat memberi gambaran kepuasan pengguna sekaligus menjadi masukan bagi pihak penyedia layanan dalam mengembangkan strategi selanjutnya.
\end{abstract}

Kata Kunci: Indihome, Kepuasan Penggguna, Servqual, dan Webqual.

\section{PENDAHULUAN}

PT. Telkom, Tbk sebagai salah satu badan usaha yang bergerak dalam bidang jasa komunikasi. Berbagai jasa teknologi dan komunikasi yang saat ini digunakan masyarakat menjadi produk yang disediakan, salah satunya penyediaan koneksi internet. Pada saat ini, PT. Telkom, Tbk dituntut untuk meningkatkan pelayanan akan sarana dan prasarana telekomunikasi yang diperlukan oleh masyarakat khususnya konsumen atau pelanggan jasa Telkom.
Hal ini, tentu saja menuntut kemampuan manajemen pelayanan untuk memberikan respon yang cepat, tepat dan akurat kepada konsumen atau pelanggan.

IndiHOME atau Indihome merupakan salah satu produk layanan dari PT. Telkom kepada masyarakat, berupa paket layanan komunikasi dan data seperti telepon rumah (voice), internet (Internet on Fiber atau High Speed Internet), dan layanan televisi interaktif (USee TV Cable, IP TV). 
Meskipun memiliki beberapa sarana untuk menampung semua keluhan pelanggan di Indonesia, namun dalam kenyataannya masih banyak keluhan pelanggan yang belum dapat terselesaikan dengan baik yang perlu diperhatikan (Kurniawati \& Manuputty, 2013).

Untuk melayani kebutuhan pelanggan Indihome dalam hal penanganan keluhan gangguan maupun permintaan pasang baru, Telkom menyediakan beberapa channel atau pilihan beberapa fitur agar pelanggan dapat dengan mudah berinteraksi dengan Telkom. Banyaknya jumlah pengguna Indihome yang akan terus bertambah, membuat PT. Telkom, Tbk harus meningkatkan pelayanan terhadap pelanggan baik untuk melayani pemasangan baru, penambahan layanan, migrasi paket, informasi tagihan hingga laporan keluhan gangguan layanan. Mengenai layanan tersebut sebenarnya Telkom sudah menyediakan beberapa cara untuk dapat melayani pelanggan diantaranya adalah dengan datang langsung ke Plasa Telkom terdekat atau melalui Call Center Telkom 147. Selain itu, Telkom juga menyediakan layanan berbasis aplikasi mobile yaitu aplikasi MyIndiHome. Aplikasi MyIndiHome sendiri saat ini (27/01/2019) di Google Playstore sudah mencapai 1 juta download dengan rating 3.1 dari skala 5 .

Dalam penelitian ini, untuk mengukur kepuasan pengguna terhadap respon cepat tanggap layanan aplikasi mobile myindihome menggunakan kombinasi metode ServQual dan WebQual. Berdasarkan teori metode service quality (ServQual) digunakan untuk mengetahui kepuasan terhadap aplikasi tersebut, apakah ada pengaruh variabel reliability, responsiveness, empathy, assurance, dan tangible terhadap kepuasan pengguna baik perorangan maupun kelompok (Firliana dkk., 2016). Sedangkan berdasarkan instrumen metode webqual 4.0 mengidentifikasi situs web berdasarkan tiga variabel yaitu usability, information quality, dan service interaction quality. Setiap variabel akan didukung dengan indikator-indikator yang menjadi kunci dalam penyususunan pernyataan yang akan diuji kepada responden. Maka hasil pengukuran tersebut menunjukkan bahwa jika variabel subyektif (ServQual) dari indeks usabilitas ditingkatkan, maka variabel obyektif dari indeks usabilitas (WebQual) juga akan meningkat secara signifikan(Hermanto dkk., 2017). 


\section{METODE}

Jenis data penelitian dibedakan menjadi data primer dan data sekunder. Namun, penelitian ini hanya menggunakan data primer. Menurut Abdillah (2018) data primer adalah data yang belum pernah diolah oleh pihak tertentu untuk kepentingan tertentu. Data primer menunjukkan keaslian informasi yang terkandung di dalam data tesebut. Data primer pada umumnya bersumber dari sumber primer, yaitu data berada pada pihak utama yang memiliki data tersebut. Data primer dalam penelitian ini diperoleh dengan memberikan kuesioner (questionnaire) kepada pengguna aplikasi mobile myindihome.

Penelitian ini dibahas mengenai deskripsi data masing-masing variabel penelitian dan pengaruh 2 variabel bebas yaitu servqual (X1) dan webqual (X2) dengan satu variabel dependen tingkat kepuasan pengguna (Y) pada penyedia jasa layanan di Kota Palembang. Pada variabel deskriptif kepuasan pengguna, penilaian dilakukan dengan 3 indikator, diantaranya adalah kesesuaian harapan, minat berkunjung kembali, dan kesediaan merekomendasikan.Terdapat variabel dimana terdapat indikatorindikator yang terdapat ada masingmasing variabel. Setiap indikator terdiri dari beberapa item pernyataan. Variabel, indikator dan juga item yang akan digunakan pada penelitian ini dijelaskan tabel berikut. Indikator yang menyusun variabel Service Quality, menggunakan seluruh indikator yang terdapat pada metode ServQual. Terdapat 5 indikator yaitu, tangible, reliability, responsiveness, assurance, dan emphaty. Item pernyataan disesuaikan dengan objek penelitian yaitu PT. Telkom, Tbk Kota Palembang sebagai penyedia layanan indihome. Indikator yang menyusun variabel Website Quality, merupakan seluruh indikator yang terdapat pada metode WebQual. Item pernyataan disesuaikan dengan objek penelitian yaitu aplikasi MyIndihome. Sedangkan indikator yang menyusun variabel User Satisfaction (Kepuasan Pengguna), merupakan indikator yang bersumber dari metode kesuksesan DeLone dan McLean (2003).

Secara umum, menurut Abdillah (2018) metode pengumpulan data penelitian dapat dibedakan menjadi metode kuesioner, observarsi, wawancara, diskusi kelompok terarah, eksperimentasi laboratorium dan lapangan. Pengumpulan data pada penelitian ini menggunakan terknik 
survey yaitu dengan menyediakan Kuesioner (Questionnaire).

Kuesioner adalah metode pengumpulan data primer menggunakan sejumlah item-item pertanyaan dengan format tertentu. Kuesioner adalah metode pengumpulan data yang paling umum digunakan dalam studi lapangan atau survei. Kuesioner memiliki keunggulan karena memuat informasi yang efektif dan efisien sesuai dengan tujuan penelitian. Kuesioner menggunakan sistem tertutup, yaitu bentuk pertanyaan yang disertai alternatif jawaban dan responden tinggal memilih salah satu alternatif jawaban tersebut.

\section{Menurut Abdillah}

Pengambilan sampel merupakan bagian penting dalam proses penelitian. Pengambilan sampel menentukan keakuratan dan ketepatan penentuan sumber data dan informasi bagi proses analisis dan pengmbilan kesimpulan. Teknik sampling pada penelitian ini menggunakan purposive sampling. Tujuan teknik pengambilan adalah teknik pemilihan sampel ketika peneliti tidak memiliki data tentang populasi dalam bentuk sampling frame dan peneliti kemudian memilih sampel berdasarkan kriteria-kriteria tertentu dan penilaian peneliti untuk mengarahkan sampel terpilih sesuai dengan tujuan penelitian.

Barclay dkk. (1995) menyatakan bahwa jumlah sampel harus lebih besar dari 10 kali jumlah variable yang diamati. Pada penelitian ini ada 9 variabel, sehingga jumlah sampel adalah minimal 90 responden. Untuk lebih menyakinkan secara statistik, penelitian ini juga akan menguji kecukupan jumlah responden berdasarkan saran dari Hair dkk. (2010) yaitu menggunakan KaiserMeyer-Olkin Measure of Sampling Adequacy (KMOMSA) dan Bartlett's Test of Sphericity (BToS). Nilai KMO antara 0,5 - 1 menunjukan jumlah sampel telah memadai. Berdasarkan nilai, mereka mengkategorikan ukuran sebagai luar biasa $(0,90$-an), sangat baik (0,80-an), baik (0,70-an), cukup $(0,60$ an) dan menyedihkan (0,50-an). Jika BToS kurang dari 0,05, kecukupan sampel signifikan.

Menurut Noor (2016) mengatakan bahwa skala pengukuran merupakan alat ukur yang digunakan untuk mengkuantifikasi informasi yang diberikan oleh konsumen jika mereka diharuskan menjawab pertanyaan yang telah dirumuskan dalam suatu kuesioner. Maka penelitian menggunakan skala 
likert summated ratings, yaitu teknik mengukur sikap dimana subjek diminta untuk mengindikasikan tingkat kesetujuan atau ketidaksetujuan mereka terhadap masing-masing pernyataan (Noor, 2016, p. 128).

Penelitian ini melihat secara objektif persepsi pelanggan terhadap layanan yang diberikan oleh pihak PT. Telkom, Tbk., sehingga penelitian ini digolongkan pada penelitian kuantitatif. Data yang dikumpulkan akan dianalisis menggunakan Teknik Analisis Data Kuantitatif.

Bagian ini menyajikan analisis data menggunakan Structural Equation Modelling (SEM), lebih khusus lagi menggunakan Partial Least Squares (PLS) untuk mengevaluasi model yang diusulkan. Ada dua langkah untuk uji validitas dan reliabilitas untuk membangun model dalam SEM menggunakan PLS. Menurut Hair dkk. (2016) secara garis besar ada dua tahap analisis data yaitu Measurement Model Analysis dan Structural Model Analysis. Sebelum dilakukan analisis tersebut, penulis akan melakukan persiapan data (data preparation) yang bertujuan membersihkan data dari hal-hal yang dapat mempengaruhi hasil.

\section{HASIL DAN PEMBAHASAN}

Berdasarkan penyebaran kuesioner terhadap 200 responden yang merupakan pelanggan indihome Kota Palembang dapat diketahui gambaran tentang usia, pendidikan, dan pekerjaan responden yang dijadikan sampel.

Berdasarkan data penelitian yang diperoleh dari penyebaran kuesioner maka diperoleh data tentang usia pengguna indihome Kota Palembang yang menjadi respon dalam penelitian ini, seperti Tabel 1.

Tabel 1. Deskripsi Usia Reponden

\begin{tabular}{|c|c|c|c|}
\hline No. & $\begin{array}{c}\text { Umur } \\
\text { (tahun) }\end{array}$ & Jumlah & $\begin{array}{c}\text { Persentase } \\
(\%)\end{array}$ \\
\hline 1. & $12-18$ & 29 & $15 \%$ \\
\hline 2. & $19-24$ & 32 & $16 \%$ \\
\hline 3. & $25-30$ & 48 & $24 \%$ \\
\hline 4. & $31-40$ & 39 & $20 \%$ \\
\hline 5. & $41-50$ & 29 & $15 \%$ \\
\hline 6. & $>51$ & 23 & $12 \%$ \\
\hline \multicolumn{2}{|c|}{ Total } & 200 & $100 \%$ \\
\hline
\end{tabular}

Tabel 1 menunjukkan bahwa sebagian besar usia pengguna indihome Kota Palembang dalam penelitian ini yang paling banyak menggunakan tingkatan umur 25 - 30 tahun sebanyak 48 pengguna. Data tersebut bisa dijadikan masukan kepada pihak penyedia jasa layanan indihome untuk lebih memperhatikan solusi keluhan yang 
seperti apa yang tepat bagi pengguna indihome.

Berdasarkan data penelitian yang diperoleh dari penyebaran kuesioner maka diperoleh data tentang pendidikan pengguna indihome Kota Palembang yang menjadi respon dalam penelitian ini, seperti Tabel 2.

Tabel 2. Deskripsi Pendidikan Responden

\begin{tabular}{|c|c|c|c|}
\hline No. & Pendidikan & Jumlah & Persentase (\%) \\
\hline 1. & SD & 12 & $6 \%$ \\
\hline 2. & SMP & 17 & $9 \%$ \\
\hline 3. & SMA & 53 & $27 \%$ \\
\hline 4. & D3 & 2 & $1 \%$ \\
\hline 5. & $\mathrm{D} 4 / \mathrm{S} 1$ & 106 & $53 \%$ \\
\hline 6. & S2 & 10 & $5 \%$ \\
\hline & Total & 200 & $100 \%$ \\
\hline
\end{tabular}

Tabel berikut menunjukkan bahwa sebagian besar pendidikan pengguna indihome dalam penelitian ini memiliki pendidikan S1 sebanyak 106 orang, sedangkan yang pendidikan SMA sebanyak 53 orang. Hal ini untuk perrhatian bagi penyedia jasa layanan indihome, bahwa pengguna indihome mayoritas berpendidikan antara SMA dan S1. Oleh karena itu lebih mengerti seperti apa yang diminati oleh pengguna indihome.

Data yang perlu disiapkan, diperiksa dan dieksplorasi sebelum melakukan analisis data statistik lebih lanjut. Langkah ini melibatkan entri data dan data screening, memeriksa missing value, memeriksa kecukupan data (unegated value), keseriusan responden, outlier, dan pengujian normalitas data.

Proses entri data yang dilakukan dengan menggabungkan dua sumber data ke dalam satu file menggunakan Microsoft Excel. Untuk membuat diskusi lebih nyaman di bagian selanjutnya, penelitian ini menyingkat nama-nama variabel sebagai berikut: User Satisfaction (Kepuasan pengguna dengan sistem saat ini), ServQual (Kualitas disisi layanan indihome), dan WebQual (Kualitas produk indihome yang diberikan dengan objek penelitian yaitu aplikasi MyIndihome).

Data dikumpulkan dari berbagai organisasi di Kota Palembang dengan menggunakan survei berbasis kertas. Berdasarkan file, data dari survei berbasis kertas dimasukkan secara manual ke dalam excel. Setiap upaya dilakukan untuk menghindari kesalahan entri data dengan memanfaatkan fitur Excel dan menjaga kompatibilitas file dengan aplikasi SPSS termasuk nilai dan label untuk variabel.

Proses penyaringan data (data screening) dimulai dengan melakukan analisis data yang hilang (missing value). 
Penyaringan data memastikan apakah data berguna dan valid untuk analisis lebih lanjut. Hair dkk. (2010) menjelaskan bahwa data yang hilang terjadi ketika nilai yang valid pada satu atau lebih variabel tidak tersedia untuk analisis. Selanjutnya, penting untuk memeriksa data yang hilang untuk mencegah masalah generalisasi hasil. Setiap data yang hilang lebih dari 5\% harus dihilangkan dari analisis akhir. Analisis menunjukkan bahwa tidak ada respon yang memiliki beberapa data hilang, responden memberikan respon yang valid.

Jika nilainya nol atau mendekati nol, data tidak berguna karena respons non varians. Hasilnya menunjukkan bahwa ditemukan 2 responden yang merespon dengan nilai yang sama persis dan yang lainnya memiliki skor 0,2 atau lebih besar, yang berarti bahwa sebagian yang lain tidak ada jawaban yang perlu dihapus karena sebagian responden terlibat dengan pertanyaan.

Eliminasi outlier adalah suatu cara mengatasi ketidaknormalan data dalam analisis SEM dengan menghilangkan data-data yang terdeteksi sebagai outlier. Hal ini karena salah satu sebab ketidaknormalan data adalah karena data memuat banyak outlier. Eliminasi outlier diawali dengan deteksi outlier yang selanjutnya dilanjutkan dengan menghilangkan data-data outlier tersebut.

Deteksi outlier dapat dilakukan dengan melihat jarak mahalonobis data tersebut, yaitu dengan meluhat keluaran AMOS bagian Observation Further of The Centroid (Mahalonobis distance). Data dikatakan sebagai outlier jika nilai $\mathrm{p} 2<0,05$.

Normalitas mengacu pada bentuk distribusi data dan karakteristik statistiknya untuk variabel metrik individu tunggal yang memenuhi distribusi normal (Hair et al., 2010). Sementara skewness digunakan untuk menggambarkan keseimbangan distribusi, kurtosis digunakan untuk menguji kerataan distribusi (Hair et al., 2010). Skewness dan kurtosis kurva normal memiliki nilai nol; kemiringan atau nilai kurtosis di atas atau di bawah nol menunjukkan penyimpangan dari normalitas. Nilai yang paling dapat diterima untuk dua statistik adalah antara -2 dan +2 . Nilai antara -3 dan +3 agar skewness dikategorikan sebagai distribusi normal. Selain itu, Kline menyatakan bahwa nilai absolut yang lebih tinggi dari 8,0 untuk kurtosis 
menunjukkan masalah. Aturan praktis nilai absolut 1 untuk skewness.

Ada beberapa opsi untuk berurusan dengan distribusi data yang tidak normal. Opsi pertama adalah melakukan uji parametrik dengan data tidak normal dengan asumsi normalitas. Hair et al. (2010) berpendapat bahwa sedikit penyimpangan dari normalitas dapat mengakibatkan sedikit ketidakakuratan dalam tes parametrik. Pilihan kedua adalah melakukan tes non-parametrik untuk data yang tidak normal. Tes non parametrik tidak mengasumsikan distribusi spesifik untuk data, meskipun tes bisa kurang kuat dibandingkan dengan uji parametrik . Opsi ketiga adalah menggunakan transformasi data sebagai obat untuk mengubah data untuk mendapatkan distribusi normal (Hair et al., 2010). Dalam opsi ini, proses transformasi menggunakan banyak fungsi matematika (seperti akar kuadrat, logaritma, atau archine) untuk mendapatkan data distribusi normal. Opsi keempat adalah menerapkan pemodelan persamaan struktural berbasis varians seperti PLS. Tidak seperti AMOS atau LISREL, PLS tidak memerlukan data terdistribusi untuk memberikan rekomendasi yang menonjol.
Penilaian validitas model pengukuran melibatkan (1) reliabilitas indikator, (2) reliabilitas konsistensi internal dan (3) validitas konstruk. Straub et al. (2004) menyarankan validitas konvergen dan validitas diskriminan untuk menilai validitas konstruk. Untuk tujuan ini, studi saat ini terutama menggunakan SmartPLS (Ringle et al., 2005) dan menggabungkan ini dengan SPSS dan Excel bila perlu.

Model pengukuran telah divalidasi melalui proses yang ketat secara sistematis pada bagian sebelumnya. Hasilnya menunjukkan bahwa semua properti penilaian reliabilitas dan validitas berada dalam rentang kesalahan yang dapat diterima. Hasil uji normalitas juga menunjukkan bahwa ada beberapa masalah dengan normalitas. Chin (2010) merekomendasikan estimasi PLS untuk kasus distribusi variabel yang tidak normal. Model struktural dinilai untuk menentukan kekuatan penjelas dari model serta untuk menguji hipotesis penelitian. Penelitian saat ini mengadaptasi Hair et al. (2014) untuk menilai validitas model struktural.

Daftar pernyataan data kuesioner yang ditunjukkan pada Tabel menunjukkan sejumlah item untuk 
diskusi. Kolom mewakili empat himpunan bagian data berdasarkan 90 responden: peringkat pentingnya untuk setiap pernyataan dan peringkat persepsi per pernyataan untuk masing-masing dari variabel yang terkait. Item kuesione ditampilkan dalam tabel untuk setiap pernyataan dan subset: mean, standard error dan standar deviasi.

Secara umum, PLS tidak memberikan interval kepercayaan untuk rute antara variabel potensial. Karena alasan seperti itu, metode 'Boot Strapping Re-sampling' biasanya digunakan untuk memverifikasi tingkat signifikansi. Dalam penelitian ini, metode 'Boot Strapping Re-sampling' telah diimplementasikan 200 kali.

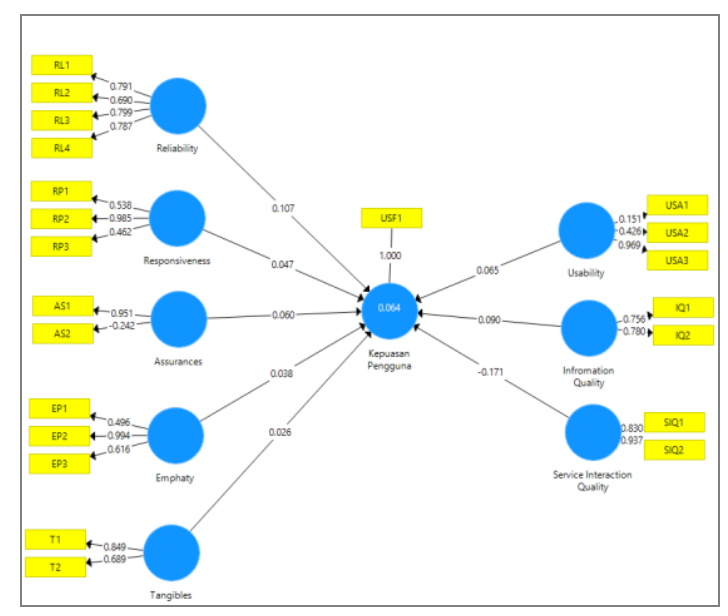

Gambar 1. Model Hasil Perhitungan SEM-

PLS

\section{PENUTUP}

Menurut hasil penelitian, kegunaan layanan indihome untuk pemakaian, lapor gangguan, serta transaksi sangat mempengaruhi kepuasan pelanggan. Namun, pengaruh interaksi telah ditemukan lemah. Estimasi kualitas layanan indihome untuk pemakaian, lapor gangguan, serta transaksi berdasarkan penggunaan model WebQual dapat dianggap secara umum sesuai dibandingkan dengan model SERVQUAL, yang merupakan model estimasi offline sebelumnya.

Mempertimbangkan situasi seperti itu, kategori yang terkait dengan estimasi kualitas layanan indihome untuk lapor gangguan, yang telah ditarik dalam penelitian ini, akan digunakan sebagai data penting untuk berbagai layanan tindak lanjut dari penyedia jasa layanan. Secara khusus, mereka akan digunakan untuk membuat model evaluasi kualitas standar yang terkait dengan layanan indihome berdasarkan aplikasi mobile myindihome.

Data yang dikumpulkan dalam penelitian ini diolah untuk memperoleh indeks metoe servqual dan indeks metode webqual dengan menerapkan pemodelan persamaan struktural. Hasil pengolahan menunjukkan bahwa jika dimensi kepuasan ditingkatkan, maka ukuran obyektif indeks usabilitas dapat meningkatkan secara signifikan. Hasil 
penelitian ini menunjukkan bahwa aspek-aspek obyektif dan subjektif yang menjadi faktor penilaian dalam mendapatkan hasil yang baik dan memuaskan dari hampir semua responden dalam menggunakan layanan myindihome.

\section{DAFTAR PUSTAKA}

Abdillah, W. (2018). Metode Penelitian Terpadu Sistem Informasi Yogyakarta: ANDI.

Barclay, D., Higgins, C., \& Thompson, R. (1995). The partial least squares (PLS) approach to casual modeling: personal computer adoption ans use as an Illustration. Technology Studies, 2(2).

DeLone, W. H., \& McLean, E. R. (2003). The DeLone and McLean model of information systems success: a ten-year update. $J$ Journal of management information systems, 19(4), 9-30.

Firliana, R., Kasih, P., \& Sulastri, H. S. (2016). Sistem Analisis Kualitas Pelayanan terhadap Tingkat Kepuasan Pelanggan menggunakan Metode Service Quality (SERVQUAL). Seminar Nasional Teknologi Informasi dan Multimedia (semnasteknomedia online), 4(1), 205-210.
Hair, J. F., Anderson, R. E., Babin, B. J., \& Black, W. C. (2010). Multivariate data analysis: A global perspective (Vol. 7): Upper Saddle River, NJ: Pearson.

Hair, J. F., Hult, G. T. M., Ringle, C. M., \& Sarstedt, M. (2016). A Primer on Partial Least Squares Structural Equation Modeling (PLS-SEM): SAGE Publications.

Hermanto, A., Supangat, S., \& Mandita, F. (2017). Evaluasi Usabilitas Layanan Sistem Informasi Akademik Berdasarkan Kombinasi ServQual dan Webqual Studi Kasus: SIAKAD Politeknik XYZ. Journal of Information Systems Engineering and Business Intelligence, 3(1), 33-39.

Kurniawati, R., \& Manuputty, A. D. (2013). Analisis Kualitas Layanan Teknologi Informasi dengan Menggunakan Framework Information Technology Infrastructure LibraryV. 3 (ITIL V. 3) DomainService Transition: Studi Kasus pada Costumer Service Area Telkom Salatiga. Jurnal Teknologi Informasi -Aiti, 10(1), 31-45.

Noor, J. (2016). Metodologi Penelitian: Skripsi, Tesis, Disertasi \& Karya Ilmiah: Kencana Prenada Media Group. 